\title{
Optimizing patient care and outcomes through the congenital heart center of the 21st century
}

\author{
Jeffery $B$ \\ B. Anderson MD \\ Devyani Chowdhury MD2 \\ Curt J. Daniels MD ${ }^{4}$ ｜ Craig E. Fleishman MD5 | Michael Gaies MD 6 \\ Jeffrey Jacobs MD7,8 | John Kugler MD ${ }^{9} \quad$ Nicolas Madsen MD ${ }^{1}$ | \\ Robert H. Beekman MD ${ }^{6} \quad$ Stacey Lihn MA ${ }^{10}$ ～Kay Stewart-Huey BSIE ${ }^{11}$ | \\ Robert Vincent MD ${ }^{11}$ | Robert Campbell MD11
}

Jean A. Connor RN PhD3

${ }^{1}$ Heart Institute, Cincinnati Children's

Hospital, Cincinnati, Ohio, USA

${ }^{2}$ Cardiology Care for Children, Lancaster,

Pennsylvania, USA

${ }^{3}$ Boston Children's Hospital, Boston,

Massachusetts, USA

${ }^{4}$ Nationwide Children's, Columbus, Ohio, USA

${ }^{5}$ The Heart Center at Arnold Palmer Hospital for Children, Orlando, Florida, USA

${ }^{6}$ University of Michigan Congenital Heart

Center, Ann Arbor, Michigan, USA

${ }^{7}$ Johns Hopkins All Children's Hospital and Florida Hospital for Children, St. Petersburg, Florida, USA

${ }^{8}$ Johns Hopkins University School of Medicine, Baltimore, Maryland, USA

${ }^{9}$ Children's Hospital \& Medical Center, Omaha, Nebraska, USA

${ }^{10}$ Sisters-by-Heart, El Segundo, California, USA

${ }^{11}$ Children's Healthcare of Atlanta, Atlanta, Georgia, USA

\section{Correspondence}

Jeffrey B. Anderson, The Heart Institute,

Cincinnati Children's Hospital Medical

Center, 3333 Burnet Ave, ML 2003,

Cincinnati, Ohio, USA.

Email: jeffrey.anderson@cchmc.org

Funding information

None

\begin{abstract}
Pediatric cardiovascular services are responding to the dynamic changes in the medical environment, including the business of medicine. The opportunity to advance our pediatric cardiology field through collaboration is now realized, permitting us to define meaningful quality metrics and establish national benchmarks through multicenter efforts. In March 2016, the American College of Cardiology hosted the first Adult Congenital/Pediatric Cardiology Section Congenital Heart Community Day. This was an open participation meeting for clinicians, administrators, patients/parents to propose metrics that optimize patient care and outcomes for a state-of-the-art congenital heart center of the 21st century. Care center collaboration helps overcome the barrier of relative small volumes at any given program. Patients and families have become active collaborative partners with care centers in the definition of acute and longitudinal outcomes and our quality metrics. Understanding programmatic metrics that create an environment to provide outstanding congenital heart care will allow centers to improve their structure, processes and ultimately outcomes, leading to an increasing number of centers that provide excellent care. This manuscript provides background, as well listing of proposed specialty domain quality metrics for centers, and thus serves as an updated baseline for the ongoing dynamic process of optimizing care and realizing patient value.
\end{abstract}

\section{KEYWORDS}

congenital heart disease, outcomes, quality, safety, value

\section{1 | INTRODUCTION}

Care for children and adults with pediatric and congenital heart disease illustrate the power and possibility of modern medicine. Continuous advancement of therapies and services available to serve patients and families has rendered previously untreatable illnesses manageable, with many individuals affected by these conditions now living into adulthood and functioning well in society. Coupled with these successes, and perhaps contributing to them, has been a rising focus by hospitals and providers on measuring patient outcomes and experience and 
enhancing transparency regarding quality of care in communication with patients and families.

In 2002, the American Academy of Pediatrics published "Guidelines for Pediatric Cardiovascular Centers." ${ }^{11}$ The objective of this statement was to describe critical elements of a pediatric cardiovascular center necessary for achieving the best patient outcomes. When this statement was written multicenter measurement and quality improvement efforts were in their early infancy. Over the past fifteen years there have been advances in our understanding of cardiac physiology, diagnostic tools and therapeutic techniques. Our understanding of important components of care associated with excellent patient outcomes has also improved.

In addition to medical and surgical advances, several other factors impact the structure and practice of congenital heart disease care. First, the volume and variety of data captured at care centers and across data registries has expanded exponentially. ${ }^{2}$ Second, there has been a heightened focus on transparency and reporting of data. This movement has been led by providers inspired by patients/families collaborating to improve practice and outcomes, patients and families seeking information to help make decisions about where to receive care, and payers interested in seeking centers with best outcomes and lowest costs. $^{3-5}$ The availability of vast outcome data allowed several external organizations to provide the public with information about hospital performance and even to create rankings of programs. The most prominent examples of public reporting in our field include US News and World Report and the Society of Thoracic Surgeons (STS). While patients and families have fought for access to clinical outcomes data, they have also advocated for systems of care and specific processes that are more patient- and family-centered, promoting shared decisionmaking principles integral to their child's care. ${ }^{6}$ Finally, clinicians and researchers shifted their focus to quality metrics beyond mortality and morbidity as important factors in defining high-value care. The Institute of Medicine provided one framework for considering outcomes and value holistically and outlined six domains of quality in healthcare: safe, effective, patient-centered, timely, efficient, and equitable. ${ }^{7}$ There is now an increased focus on understanding patient and family experience as a metric of value in care delivered.

The aim of this project was to describe the structure, function, and critical outcome measures that would allow the congenital heart center of the 21st century to achieve the best value for patients with congenital heart disease. Uniquely, this particular project was imagined and executed by providers, rather than centers or external organizations, and has been inspired and guided by the voice of parents and patients, each group demanding a better understanding of what drives great short and long-term clinical outcomes.

\section{2 | METHODS}

The topic of programmatic metrics in congenital heart disease centers was the subject of the first Congenital Heart Community Day, held in conjunction with the 2016 American College of Cardiology Annual Meeting. This full day was attended by a broad representative group of
TABLE 1 Domains for metric development

\begin{tabular}{l} 
Administration \\
Adult congenital care \\
Ambulatory \\
Cardiothoracic surgery \\
Cardiac critical care \\
\hline Electrophysiology \\
Inpatient units \\
\hline Interventional cardiology \\
\hline Noninvasive imaging \\
\hline Nursing
\end{tabular}

cardiologists, surgeons, nurses, parents and administrators. Through plenary talks and breakout sessions, groups from multiple domains within the larger cardiac care community began to propose metrics that define great congenital heart programs using several foundational principles. These topics were further discussed and refined at the Twelfth Annual Meeting of The Multi-Societal Database Committee for Pediatric and Congenital Heart Disease (Wednesday, August 24, 2016 and Thursday, August 25, 2016 at the Emory Conference Center, Atlanta, Georgia).

In defining appropriate programmatic metrics we used several foundational principles. Donabedian, a physician and health services researcher, developed a conceptual model that frames health services and quality of care around three categories: structure, process and outcomes. Structure describes the context in which care is delivered, and includes physical structures, supplies and equipment. Process is the flow and interaction of patients through the care delivery system and the interaction with care givers. Finally, outcomes refer to the health status of the patient receiving care in the system. ${ }^{8}$ Porter further delineated the complexity of health outcomes in his model of value in healthcare. Outcomes, according to Porter, include short-term outcomes, such as mortality, but also must include long-term functional outcomes as well. ${ }^{9}$

We followed the frameworks outlined by Donabedian and Porter and organized our discussion of metrics around process, structure and outcome. ${ }^{8,9}$ The first draft of these metrics was created by workgroups during the Congenital Heart Community Day. For each cardiology domain (Table 1) project leaders defined programmatic metrics for their domain based on best available data, evidence and content expertise. Finally, each group defined gaps that currently exist in our knowledge about programmatic quality and outcomes, to act as a guide for future research on more refined metrics. What follows is a description and list of proposed programmatic metrics from each domain.

\section{$2.1 \mid$ Administration}

The congenital heart center Administration domain requires close alignment with clinical care. Physician and administrative leadership optimally function through a dyad relationship, to ensure that all aspects of the congenital heart center meet the needs of patients and families. Physician leadership input regarding strategic direction, financial 
TABLE 2 Administration metrics

\begin{tabular}{|c|c|c|}
\hline Metric & Domain & Definition \\
\hline 1. & Structure & Core certifications for Physicians, APPs, and Nurses (Board Certification, APP Certification, CCNC) \\
\hline 2. & Structure & Nurse to Patient Ratio \\
\hline 3. & Structure & Core Accreditation/Credentialing/Recognition: Joint Commission, Beacon, Magnet, Sub-Specialty Accreditation Programs \\
\hline 4. & Structure & $\begin{array}{l}\text { Dedicated Services/Programs/Facilities: Dedicated Cardiac ORs; Dedicated Cardiac Anesthesia Services; Inpatient } \\
\text { Cardiology Consultation; Cardiac Intensive Care Unit; Remote monitoring of Cardiac patients (telemetry); Noninva- } \\
\text { sive cardiac imaging, CT and MRI; Cardiac Interventional Cath Lab/Diagnostic Cath Lab/EP Lab; Adult Congenital } \\
\text { Heart Program; ECMO; Heart Transplant and Heart Failure Program; Mechanical Device Program; Cardiac Genetics } \\
\text { Clinic; Cardiac Neurodevelopmental Care Program; Pediatric Cardiac Anesthesia services; Diagnostic modalities } \\
\text { (Echo, CT, cMRI); Cardiopulmonary Exercise testing; Telemedicine; Specialty Programs (Fetal Cardiology, Aortopathy, } \\
\text { Arrhythmia, Pulmonary Hypertension, Preventive Cardiology, etc). } \\
\text { Consultative services to manage noncardiac issues in the cardiac patient (neurology, nephrology, GI, infectious disease, } \\
\text { nutrition, social work, pharmacy, transfusion services, etc). }\end{array}$ \\
\hline 5. & Structure & $\begin{array}{l}\text { Participation in Core Clinical Registries/Collaboratives: STS Congenital Cardiac Surgery; STS Congenital Cardiac } \\
\text { Anesthesia Society; NCDR-IMPACT; C3PO-QI; PC }{ }^{4} \text { or VPS; PAC3; National Pediatric Cardiology Quality Improvement } \\
\text { Collaborative (NPC-QIC); Solutions for Patient Safety Collaborative (SPS); ELSO }\end{array}$ \\
\hline 7. & Process & Transparency of Surgical Outcomes \\
\hline 8. & Process & Transparency of Patient Experience \\
\hline 9. & Process & Surgery cancellation rate (not related to patient illness or cause) \\
\hline 10. & Process & Standardized physician communication for inpatient care and discharge, postdischarge follow-up care \\
\hline
\end{tabular}

decisions, programs, and clinician performance metrics is vital. Communication with all members of the program ensures alignment with mission and heightens engagement of staff. Structure and process are cornerstones of the Administration domain, to ensure that comprehensive clinical facilities, equipment, skilled personnel, and pertinent resources are available. Patients with complex congenital heart defects require advanced clinical services and therapies/treatments, advanced technology (eg, ECMO, mechanical ventricular assist device), clinical support services, and seamless transition or continuation to adult congenital heart care. Comprehensive specialty programs, (arrhythmia, pulmonary hypertension, aorta and vascular, neurodevelopmental care, etc) and services support need to be readily available. A comprehensive outpatient network allows local care to be delivered locally in the communities, also ensuring efficient and effective communication with the inpatient center through the use of electronic medical records. Advanced health information technology is now the standard and becomes a cornerstone for accountable care organizations or clinically integrated networks. Timely access to care (perhaps best quantitatively measured as cancellation rate for surgical procedures or time to third next available appointment in the outpatient arena) has become an important outcome measure for busy and at-capacity heart centers. Centralized cardiac patient scheduling and concierge services assist with coordination of care and patient experience.

The Administration domain is also responsible for the documentation of quality for providers and the heart program. Certification of programmatic structures and processes and the credentialing of clinical care providers and staff, including maintenance of certification, becomes the responsibility for the congenital heart center. Children's hospitals and pediatric cardiac programs are now ranked through an annual US News and World Report survey. Centers are externally accredited through Joint Commission, Magnet, or Beacon recognition, and other subspecialty accreditation programs. Centers should participate in key national clinical registries and patient care and safety collaboratives for benchmarking and adoption of best practices, generation of centerspecific registry-documented results, and transparency through public reporting. Engagement of the patient and family is essential in improving operations and their experience. Use of a survey instrument such as HCAHPS (Hospital Consumer Assessment of Healthcare Providers and Systems) measures patients' perceptions of their hospital experience. ${ }^{10}$ The HCAHPS survey is an example of an experience survey that provides a national standard for collecting and publicly reporting information about patient experience. The engagement of families who actively participate in a formal advisory role will assist the center in improving the day-to-day operations and patient/family experience.

For the business of medicine, it is expected that centers will begin transitioning from volume-based care (fee for service) to a value-based reimbursement structure (fee for value) with evolving contract and reimbursement strategies. Fee for value payment models prompt a center to deliver the best care at the lowest cost. As centers aim to respond to the changing market forces, they may consider involvement with clinically integrated networks for demonstrating patient care coordination. Participation with group purchasing organizations may allow for competitive pricing on supply/ equipment resources. ${ }^{11}$ Physician-developed clinical pathways can reduce error and eliminate unnecessary variability which may improve quality of care and reduce costs. Implementing team-based models utilizing advance practice providers (APPs) to extend physicians and to manage clinical programs may allow for more effective and efficient far reaching care delivery. Suggested administrative metrics can be found in Table 2 . 


\section{2 | Adult congenital}

The care of adults with congenital heart disease and the subspecialty cardiovascular field of adult congenital heart disease (ACHD) have rapidly developed over the past several decades and in parallel the recognition and importance of ACHD quality metrics (QM). The ACHD domain benefited from ACHD patient and family collaboration, leading the way to shared decision making and definition of meaningful quality metrics. The 2008 ACC/AHA guidelines for the management of adults with congenital heart disease set the stage for future ACHD quality measures and metrics. ${ }^{12}$ By providing for the first time weighted, evidence-based guidelines, structured in a lesion-specific format, the blueprint was in place for lesion-specific quality metrics. Developed over a several-year process, 55 quality indicators were proposed for 6 ACHD conditions in 2013. ${ }^{13}$ The process to derive the first set of ACHD quality indicators was based on utilizing an expert panel reviewing previously published ACHD guidelines and proposing indicators that met standards for validity and feasibility, eventually paring down to the final set of measures. During this same time, the ACC through the ACPC council developed the Quality Metric Working Group to propose CHD QMs. The ACHD working group in cooperation with the quality metric working group developed the first CHD QM-Complete Aortic Evaluation for Adults with Repaired Coarctation of the Aorta. The 24 QMs listed through the ACPC section can be found on the ACPC Quality Network website. ${ }^{14}$

Although the field of ACHD had made great strides through the 2008 ACC/AHA ACHD Care Guidelines and the 2013 ACHD lesion specific quality indicators, there still was great need to develop more structured QMs. As early as 2001, with the 32nd Bethesda Conference on the Care of the Adult with Congenital Heart Disease, experts had proposed the development of ACHD care centers and specific ACHD training for cardiologists interested in caring for this population. ${ }^{15}$ ACHD care centers/programs would create a care model that included not only the ACHD cardiologist, but advanced practice practitioners, and subspecialists in related fields that care for the ACHD patient; for example, interventional cardiology, electrophysiology, cardiothoracic surgery, echocardiography, intensive care. To this point only proposed as an important QM, Marelli and colleagues demonstrated as an outcome QM that patients referred to specialized ACHD programs in Canada experienced a significant reduction in mortality. ${ }^{16}$ In 2012, the Adult Congenital Heart Association (ACHA) took on the challenge to develop accredited ACHD Care Centers meeting criteria standards through a detailed application and a site visit. The ACHA Program Accreditation process embeds QM throughout the proposed standards and criteria that must be met to become accredited. ${ }^{17}$ There are 19 sections and over 100 individual ACHD care criteria. The accredited care centers will develop quality initiatives through the QM sharing among the centers.

To meet the needs of the ACHD patients and the standards of an ACHD care center, in 2007 a proposal was submitted to the American Board of Internal Medicine and simultaneously to the American Board of Pediatrics to create a subspecialty board certification for ACHD. In 2012, ACHD subspecialty certification was approved by the American
TABLE 3 Adult congenital metrics

\begin{tabular}{|c|c|c|}
\hline Metric & Domain & Definition \\
\hline 1. & Structure & $\begin{array}{l}\text { ACHD lesion-specific quality indicators as pub- } \\
\text { lished }^{13}\end{array}$ \\
\hline 2. & Structure & $\begin{array}{l}\text { Physicians caring for ACHD patients are ACHD } \\
\text { ABIM/ABP Board Certified }\end{array}$ \\
\hline 3. & Structure & Program is ACHD Accredited \\
\hline 4. & Structure & $\begin{array}{l}\text { ACHD cardiologists complete an AGME ap- } \\
\text { proved fellowship training program }\end{array}$ \\
\hline
\end{tabular}

Board of Medical Specialties and in October 2015, the first ACHD certifying board examination was administered. Accreditation Council for Graduate Medical Education (ACGME) approval for ACHD training followed board certification, and a 2-year curriculum was approved to be completed after either internal medicine or pediatric cardiology training. Both $A B I M / A B P$ ACHD board certification and ACGME ACHD training programs are structured QMs meeting the highest standards for training and certifying physicians in the US.

Both process and structure QMs have been developed in ACHD to improve the care of $A C H D$ patients and form a basis for quality improvement. We now have ABM/ABP board certified cardiologists incorporated into an ACHA-accredited program collecting QM data and developing multispecialty quality initiatives. The field is primed for improved access and quality of care delivered to this underserved population. Suggested Adult congenital metrics can be found in Table 3.

\section{3 | Ambulatory}

Measurement of quality care in ambulatory pediatric cardiology has lagged behind other domains of the service line, for example, cardiac intensive care unit, interventional catheterization laboratory, and cardiac surgery. While many pediatric outpatients are followed for complex cardiac diagnoses after multiple interventional and surgical procedures, another large volume of patients is evaluated for what ultimately proves to be noncardiac signs and symptoms. In the adult cardiology sphere, the NCDR PINNACLE registry is the largest observational outpatient cardiac registry in the world, for patients with coronary disease, hypertension, heart failure, or atrial fibrillation. ${ }^{18} \mathrm{Sim}$ ilar evidence-based physician performance metrics do not yet exist for pediatric cardiology. Only recently, the ACC has undertaken a process to develop quality metrics in 5 areas of interest-chest pain, postoperative tetralogy of Fallot, postoperative arterial switch repair for transposition of the great arteries, Kawasaki disease, and infectious disease issues (flu vaccine, SBE prophylaxis, Synagis, rheumatic fever). A description of the development of these metrics has been published. ${ }^{19}$ These metrics are currently being operationalized through the ACC ACPC Quality Network (QNet). ${ }^{20}$ Most of these metrics are process measures; efforts to develop patient outcome measures should be supported.

The development of, and endorsement of, multicenter clinical care pathways may help guide outpatient diagnosis and treatment and eliminate unnecessary variability. Appropriate use criteria for 
echocardiography during the initial evaluation of patients represent a first step to direct imaging based on vetted criteria. ${ }^{21}$ The National Pediatric Cardiac Quality Improvement Collaborative (NPCQIC) has proven highly successful to advance best practice care for the management of interstage patients with hypoplastic left heart syndrome. ${ }^{22}$ This multicenter collaboration amongst physicians, other cardiac care team staff, and families has generated protocols and check lists that are optimizing patient outcome.

Another methodology that has demonstrated improvement in approaches to outpatient management has been the Standardized Clinical Assessment and Management Plans (SCAMPs) program. ${ }^{23}$ SCAMPs act as clinical guidelines but permit knowledge and experience-based diversions from suggested guidelines. This approach has been applied to diverse pediatric cardiology conditions such as pediatric chest pain, syncope, balloon dilation for congenital aortic stenosis, and the postoperative management of the arterial switch operation, demonstrating reductions in resource utilization while maintaining quality of care. ${ }^{24-27}$ This standardized approach to cardiac care, along with methods such as appropriate use criteria, improve care while minimizing overutilization of resources.

Access to care, and cost of delivering these services, is becoming a focal point for cardiac service lines. Time to third next available appointment has been proposed as a standard process measure but may not be applicable to specialty programs such as pulmonary hypertension, aortopathy, and so forth. that meet infrequently. Provision of comprehensive noninvasive diagnostic services in outpatient offices is an expensive proposition, which may be offset through the alternative care delivery model of telemedicine and/or the development of teambased care, with advanced practice providers supplanting physicians.

One of the major changes in delivery of ambulatory care is the development of integrated practice units (IPUs) which engage multidisciplinary specialists and nonclinical staff to provide comprehensive care of complex patients. Examples include single ventricle survivorship programs and neurodevelopmental assessment programs, now present in many large US congenital heart disease programs. Similarly, arrhythmia services and sudden cardiac arrest programs, heart failure programs, pulmonary artery hypertension and aortopathy programs are now being developed at many centers to provide care for these complex patient subsets.

The field of ambulatory pediatric cardiology provides a ripe target for the development of objective structure, process, and patient outcome metrics. Collaboration among programs, which can be advanced through the ACC ACPC Section, should be furthered. Suggested Adult congenital metrics can be found in Table 4.

\section{4 | Cardiac critical care}

Cardiac critical care represents a key discipline necessary to achieve excellent outcomes at successful congenital heart centers. It is imperative to develop a clear understanding of the critical care team's impact on patient outcomes and the quality of care provided in cardiac intensive care units ( $\mathrm{CICU})$. Multiple databases now exist to measure and understand variation in practice and outcomes. Two primarily North
TABLE 4 Ambulatory metrics

\begin{tabular}{|c|c|c|}
\hline Metric & Domain & Definition \\
\hline 1. & Structure & $\begin{array}{l}\text { Participation in quality improvement programs: } \\
\text { NPCQIC, ACC QNet }\end{array}$ \\
\hline 2. & Structure & $\begin{array}{l}\text { Availability of comprehensive noninvasive ima- } \\
\text { ging, on-site or through telemedicine }\end{array}$ \\
\hline 3. & Structure & $\begin{array}{l}\text { Availability of IPU programs and cardiac sub- } \\
\text { specialists, including electrophysiology, heart } \\
\text { failure, preventive cardiology, adult congenital, } \\
\text { cardiovascular genetics, cardiac neurodeve- } \\
\text { lopmental follow up, fetal cardiology, pulmon- } \\
\text { ary hypertension }\end{array}$ \\
\hline 4. & Process & ACC approved ambulatory quality metrics ${ }^{19}$ \\
\hline 5. & Process & $\begin{array}{l}\text { Utilization of standardized clinical guidelines for } \\
\text { outpatient management }\end{array}$ \\
\hline 6. & Process & $\begin{array}{l}\text { Measurement of patient access to outpatient } \\
\text { clinics }\end{array}$ \\
\hline 7. & Process & $\begin{array}{l}\text { Timely structured communication to referring } \\
\text { physicians }\end{array}$ \\
\hline
\end{tabular}

American databases-the Virtual PICU System (VPS, LLC, Los Angeles) and the Pediatric Cardiac Critical Care Consortium $\left(\mathrm{PC}^{4}\right)$ clinical registry-focus solely on critically-ill patients, while many others include some data related to critical care (eg, surgical databases). Of these, the $\mathrm{PC}^{4}$ clinical registry is the only database exclusively dedicated to the cardiac critical care population.

Outcome measures used for pediatric cardiac critical care quality assessment should reflect the competence and performance of the $\mathrm{CICU}$ team, and be independent of care provided and outcomes realized prior and subsequent to the $\mathrm{CICU}$ admission. Ideal metrics of $\mathrm{CICU}$ quality would be outcome measures (as opposed to structure or process measures) and appropriately risk-adjusted to account for patient factors. Existing risk-adjustment models used in cardiac surgical and general pediatric critical care outcomes assessment are insufficient for measuring $\mathrm{CICU}$ performance, particularly when considering quality of postoperative care. Further, most existing methods focus on mortality as the clinical endpoint, and several nonmortality metrics such as complications, functional status at discharge, and resource utilization may be important markers of quality in the $\mathrm{CICU}$. A number of properly adjusted metrics will be available in the near future. When considering structure and process measures, evidence to support an association between these measures and outcomes in $\mathrm{CICU}$ patient populations is weak at best.

Further complicating the approach to outcomes assessment and defining quality in the $\mathrm{CICU}$ is the heterogeneity of hospital inpatient service structure and the interdependence of $\mathrm{CICU}$ and non-ICU/ward resources. Potential metrics such as $\mathrm{CICU}$ readmissions and $\mathrm{CICU}$ length of stay can be difficult to measure and/or hard to interpret across hospitals due to these system differences. Proposed metrics should account for these differences and reflect the quality of $\mathrm{CICU}$ care and decision making independent of what structures and resources exist in non-CICU wards. Further efforts to integrate quality assessment with clinicians and researchers focusing on non-ICU inpatient 
TABLE 5 Cardiac critical care metrics

\begin{tabular}{lll}
\hline Metric & Domain & Definition \\
\hline 1. & Outcome & $\begin{array}{c}\text { Adjusted CICU postoperative mortality (standardized mortality ratio or adjusted rate) calculated using either (a) } \\
\text { PC4 surgical mortality model or (b) VPS PICSIM model }\end{array}$ \\
\hline 2. & Outcome & $\begin{array}{c}\text { Adjusted CICU medical mortality (standardized mortality ratio or adjusted rate) calculated using either (a) PC4 } \\
\text { medical mortality model or (b) PRISM-III }\end{array}$ \\
\hline 3. & Outcome & Risk-adjusted rate of unplanned CICU readmissions within 48 hours of transfer or discharge \\
\hline 4. & Outcome & Risk-adjusted postoperative CICU length of stay \\
\hline 5. & Outcome & Risk-adjusted extubation failure rate (\% reintubation within 48 hours after planned extubation) \\
\hline 6. & Outcome & Risk-adjusted cardiac arrest incidence rate \\
\hline 6. & Outcome & Device-associated infection rates (CLABSI, CAUTI) \\
\hline 8. & Structure & Participation in a multi-institutional ICU clinical registry and/or quality improvement collaborative \\
\hline 9. & Structure & Program to provide ECLS \\
\hline 10. & Structure & Aggregate nursing education/experience and staffing (hours per patient day) \\
\hline 11. & Process & Resuscitation debriefing program \\
\hline 12. & Process & Structured OR to ICU handoff following surgical procedures \\
\hline
\end{tabular}

care will be imperative to best inform congenital heart centers on outcomes and performance. Suggested Cardiac Critical Care metrics can be found in Table 5 .

\section{5 | Cardiothoracic surgery}

The Society of Thoracic Surgeons (STS) and the Congenital Heart Surgeons' Society (CHSS) have endorsed 21 metrics to assess the quality of care delivered to patients with pediatric and congenital cardiac disease undergoing cardiac surgery. ${ }^{28}$ Published in 2012, these 21 "Quality Measures for Congenital and Pediatric Cardiac Surgery" were developed by STS and are organized according to Donabedian's Triad of Structure, Process, and Outcome, with 5 structure measures, 6 process measures, and 7 outcome measures. ${ }^{8}$ Of these 21 quality measures published by STS and CHSS, three have been endorsed by the National Quality Forum. In addition, the National Quality Forum has endorsed a fourth quality measure developed by STS: Risk-adjusted operative mortality.

Risk-adjusted operative mortality for pediatric and congenital heart surgery is reported using the 2014 STS Congenital Heart Surgery Database (CHSD) Mortality Risk Model, which facilitates description of Operative Mortality adjusted both for procedural factors and for patient level factors. ${ }^{29-32}$ This model, which includes procedural factors as well as individual patient factors, is the most comprehensive and most sophisticated risk model for congenital and pediatric heart surgery in use at the present time. ${ }^{32}$ Assessment of model fit and discrimination in the development sample and the validation sample revealed overall C statistics of 0.875 and 0.858 , respectively. Coefficients for variables in the model are re-estimated every six months to ensure that the model remains well calibrated for its use as a platform for benchmarking programmatic outcomes to national aggregate data and also for public reporting of pediatric and congenital cardiac surgical programmatic outcomes. In the future, when models have been developed that encompass other outcomes in addition to mortality, it will be possible to assess pediatric and congenital cardiac surgical performance using a multidomain composite metric that incorporates both mortality and morbidity, adjusting for the operation performed and for patientspecific factors. ${ }^{29}$ It is expected that, in the future, the entirety of this information will also be publicly reported.

Because over $95 \%$ of programs performing pediatric cardiac surgery submit data to the STS CHSD, the current national aggregate congenital and pediatric cardiac surgical outcomes contained in STS CHSD can serve as a platform for benchmarking performance and improving quality. These activities of outcomes analysis and quality improvement will ultimately allow congenital heart centers to provide better care for patients. Suggested Cardiothoracic surgery metrics can be found in Table 6. The full set of 21 "Quality Measures for Congenital and Pediatric Cardiac Surgery" developed by STS have been previously published. ${ }^{8}$

\section{6 | Electrophysiology}

Arrhythmia management, particularly cardiac ablation procedures and cardiac implantable electronic devices (CIEDs) - implantable cardiac

TABLE 6 Cardiothoracic surgery metrics

\begin{tabular}{|c|c|c|}
\hline Metric & Domain & Definition $(*=\mathrm{NQF}$ endorsed) \\
\hline 1. & Outcome & ${ }^{*}$ Risk-adjusted operative mortality \\
\hline 2 & Outcome & $\begin{array}{l}{ }^{*} \text { Operative Mortality Stratified by the Five STS- } \\
\text { EACTS Mortality Levels }\end{array}$ \\
\hline 3. & Structure & $\begin{array}{l}\text { *Participation in a National Database for Pediatric } \\
\text { and Congenital Heart Surgery }\end{array}$ \\
\hline 4. & Structure & $\begin{array}{l}\text { *Surgical volume for Pediatric and Congenital Heart } \\
\text { Surgery: Total Programmatic Volume and Pro- } \\
\text { grammatic Volume Stratified by the Five STS- } \\
\text { EACTS Mortality Categories }\end{array}$ \\
\hline
\end{tabular}

The full set of 21 "Quality Measures for Congenital and Pediatric Cardiac Surgery" developed by STS have been previously published. ${ }^{8}$ 
TABLE 7 Electrophysiology metrics

\begin{tabular}{|c|c|c|}
\hline Metric & Domain & Definition \\
\hline 1. & Outcome & $\begin{array}{l}\text { Proportion of manifest and concealed accessory pathways with an acute outcome of "elimination of } \\
\text { anterograde conduction" }\end{array}$ \\
\hline 2. & Outcome & $\begin{array}{l}\text { Proportion of AV nodal reentrant tachycardia procedures with an acute outcome of either Elimination of slow } \\
\text { pathway conduction or persistence of slow pathway conduction (with single echos but no inducible } \\
\text { tachycardia) }\end{array}$ \\
\hline 3. & Outcome & Proportion of atrial tachycardia procedures with acute procedural outcome of "substrate eliminated" \\
\hline 4. & Outcome & One year recurrence rate after acutely successful procedure for \#1-4 above \\
\hline 5. & Outcome & $\begin{array}{l}\text { Proportion of diagnostic and ablation electrophysiology procedures with a major intra or postprocedure } \\
\text { adverse event }\end{array}$ \\
\hline 6. & Outcome & Dose Area Product (cGy-cm2) during cardiac ablation procedure \\
\hline 7. & Structure & Participation in national database for pediatric electrophysiology diagnosis and treatment \\
\hline 8. & Structure & Intersocietal Accreditation Commission Accreditation of Electrophysiology Program \\
\hline 9. & Structure & $\begin{array}{l}\text { Participation in a CIED (cardiac implantable electronic devices) registry, documenting indications, procedural } \\
\text { complications, approach, procedure success }\end{array}$ \\
\hline 10. & Structure & $\begin{array}{l}\text { Presence of a dedicated electrophysiology/arrhythmia program, including (a) } 24 / 7 / 365 \text { pacemaker and ICD } \\
\text { interrogation and management, }(b) \text { comprehensive electrophysiology procedure laboratory including } \\
\text { dedicated EP staff and technological support, radiofrequency and cryoablation technology, and EP mapping } \\
\text { systems, (c) outpatient channelopathy and sudden cardiac arrest program. }\end{array}$ \\
\hline 11. & Process & Preprocedure conference with extended timeout \\
\hline 12. & Process & Use of a formal (written) protocol/checklist for post procedure handoff to ICU, ward, or recovery unit \\
\hline 13. & Process & $\begin{array}{l}\text { Use of a radiation reduction protocol-strategy and radiation exposure tracking; establish absolute radiation } \\
\text { dose target for above }(\# 1-4) \text { tachycardia ablation substrates }\end{array}$ \\
\hline
\end{tabular}

defibrillators, pacemakers, cardiac resynchronization therapies - lends itself toward quality metric and outcomes measurement. Data for quality metric and outcome measurement in pediatric electrophysiology was first considered by the Pediatric Electrophysiology Society, which began informally meeting in the early 1980 s to discuss pediatric patients with arrhythmias. The name subsequently changed to the Pediatric and Congenital Electrophysiology Society (PACES) to reflect the inclusion of the growing adult congenital population, with additional providers and centers. The Pediatric Radiofrequency Catheter Ablation Registry (1991-1999), a voluntary procedural registry, evaluated early procedural successes and failures, procedure and fluoroscopy times, arrhythmia recurrence following initially successful procedures, and demonstrated the concept of a procedural learning curve. $^{33}$ Prospective Assessment after Pediatric Cardiac Ablation (PAPCA) was a 1999-2003 prospective study and clinical registry. ${ }^{34}$ PAPCA further defined successes, complications, and recurrences of procedures stratified by the underlying electrophysiological substrate, documented a modest decrease in average fluoroscopy times compared to the initial ablation registry, and identified no substantive evidence for inadvertent injury to cardiac valves or coronary arteries as a result of a radiofrequency ablation procedure. These registries have come and gone, now replaced with the Multicenter Pediatric and Adult Congenital EP Quality (MAP-IT) registry, affiliated with the IMPACT registry through the NCDR. MAP-IT has the promise and potential to define current era outcomes in the presence of new ablation technologies (eg, cryoablation), the use of advanced imaging and diagnostic modalities (eg, fluoroless imaging), and an increasing ACHD patient population. ${ }^{35,36}$ This registry should provide the infrastructure for quality assurance and multicenter research. All 3 registries have provided individual center and provider performance relative to national performance benchmarks. The adoption of standardized quality of life surveys for subjective assessment of arrhythmia relief and the development of longitudinal long-term outcomes should be pursued.

CIEDs represent expensive and effective treatment options for many patients, and thus warrant outcome measurement and reporting. Published guidelines exist for appropriate implantation of these devices. ${ }^{37}$ Outcome measures can and should include indication for implantation, underlying substrate (electrophysiologic substrate and/or the presence of structural heart defects), procedural approach (epicardial, transvenous, subcutaneous), as well as acute and long-term outcomes including successes and complications. Pediatric and ACHD patients can be tracked through the currently available NCDR ICD registry.

In addition to outcome metrics, pediatric electrophysiology has learned from other procedural fields to incorporate safety process measures to their procedures, especially in the areas of procedural communication and utilizing checklists. Finally, as with other specialties, it is felt that participation in data sharing and learning from others through national registries is an important marker of quality in pediatric electrophysiology. Suggested Electrophysiology metrics can be found in Table 7.

\section{7 | Inpatient care}

Hospital-based cardiac care outside of the intensive care unit is an emerging field of interest and investment within pediatric cardiology. 
Care on these inpatient units, increasingly referred to as Acute Care Units, aims to achieve excellent, efficient, and cost-effective surgical and medical outcomes. As a result, there has been a recent sea change of collective attention directed toward the unique elements of care in these units.

The greatly improved pediatric cardiology mortality statistics have cast a spotlight on other measures of clinical care associated with hospitalization, such as complications, medium- and long-term morbidities, and the cost and resources necessary to deliver desired outcomes. ${ }^{38}$ Critical care databases, namely the Virtual PICU System (VPS, LLC, Los Angeles) and the Pediatric Cardiac Critical Care Consortium ( $\left.\mathrm{PC}^{4}\right)$ clinical registry as mentioned previously, aim to measure and understand variation in practice and outcomes.

In 2015, the Pediatric Acute Care Cardiology Collaborative (PAC ${ }^{3}$ ) emerged to improve care and outcomes in Acute Care Units. The aim of PAC $^{3}$ is to improve the safety and quality of pediatric inpatient cardiac care with a focus on in-hospital short- and long-term outcomes and the associated transition to outpatient care in a fashion that is thoughtful, validated, transparent, sustained, and shareable. The approach of PAC $^{3}$ is intended to dovetail with the quality measures of $\mathrm{PC}^{4}$ with an emphasis on outcome measures. The registry will be appropriately risk-adjusted to account for case-mix patient factors.

Multiple cardiac centers across North America participate in $\mathrm{PAC}^{3}$. The data dictionary for the $\mathrm{PAC}^{3}$ registry has been developed and data will be collected starting in 2018. Ultimately, the goal is to develop risk-adjustment models that can be used to transparently compare valuable outcome data across member centers (in an effort to provide an enhanced continuum of newly acquired knowledge, data definitions have been standardized with those of $\mathrm{PC}^{4}$ and STS whenever possible). Comparison of data is intended to drive multicenter quality improvement work similar in scope to what was achieved by the early extubation trial conducted by the Pediatric Heart Network. ${ }^{39}$ The first such $\mathrm{PAC}^{3}$ effort is an ongoing multicenter quality improvement project with the objective to collectively reduce postoperative chest tube duration, in an attempt to ultimately shorten hospital length of stay, lower costs, and provide immediate patient benefit. Additionally, structure and practice variation measures have already been collected across all $\mathrm{PAC}^{3}$ member sites. Evidence to support an association between these measures and the desired outcome measures will require time to determine. Suggested Inpatient unit metrics can be found in Table 8.

\subsection{Interventional cardiology}

Clinical outcomes in the cardiac catheterization laboratory are central to overall clinical outcomes in a congenital heart program. There have been several clinical registries related to outcomes for cardiac catheterization procedures over the last several decades. The Valvuloplasty and Angioplasty of Congenital Anomalies (VACA) registry in the early 1990s was a voluntary registry of 27 institutions that published outcomes on several different procedures and included some rudimentary safety data. ${ }^{40,41}$

Food and Drug Administration (FDA) device trials for ASD, VSD, and PDA devices gathered safety and efficacy data on device
TABLE 8 Inpatient unit metrics

\begin{tabular}{|c|c|c|}
\hline Metric & Domain & Definition \\
\hline 1. & Outcome & $\begin{array}{l}\text { Postoperative inpatient acute care unit length of } \\
\text { stay (Risk-adjusted) }\end{array}$ \\
\hline 2. & Outcome & Rate of hospital discharge before noon \\
\hline 3. & Outcome & $\begin{array}{l}\text { Rate of unplanned inpatient readmission within } 7 \\
\text { and } 30 \text { days of hospital discharge (Risk- } \\
\text { adjusted) }\end{array}$ \\
\hline 4. & Outcome & $\begin{array}{l}\text { Rate of unplanned ICU readmissions within } 48 \\
\text { hours of transfer to the inpatient acute care } \\
\text { unit (Risk-adjusted) }\end{array}$ \\
\hline 5. & Outcome & $\begin{array}{l}\text { Rate of unplanned ICU transfer at any time in the } \\
\text { hospitalization that leads to critical escalation } \\
\text { of care within one hour (intubation, initiation } \\
\text { of inotropes, ECMO) (Risk-adjusted) }\end{array}$ \\
\hline 6. & Outcome & $\begin{array}{l}\text { Chest tube replacement (\% chest tube replace- } \\
\text { ment within } 48 \text { hours after removal) (Risk- } \\
\text { adjusted) }\end{array}$ \\
\hline 7. & Outcome & $\begin{array}{l}\text { Device-associated infection rates (CLABSI, } \\
\text { CAUTI) }\end{array}$ \\
\hline 8. & Outcome & $\begin{array}{l}\text { Total cost of postsurgical care for STS benchmark } \\
\text { surgeries }\end{array}$ \\
\hline 10. & Structure & $\begin{array}{l}\text { Participation in multi-institutional inpatient acute } \\
\text { care unit clinical registry and/or quality im- } \\
\text { provement collaborative }\end{array}$ \\
\hline 11. & Structure & $\begin{array}{l}\text { Aggregate nursing education/experience and } \\
\text { staffing (hours per patient day) }\end{array}$ \\
\hline 12. & Structure & $\begin{array}{l}\text { Utilization of a dedicated inpatient unit clinical } \\
\text { staff (physicians and midlevel providers) }\end{array}$ \\
\hline 13. & Structure & $\begin{array}{l}\text { Postsurgical ambulation program (patients }>3 \\
\text { years of age) }\end{array}$ \\
\hline 14. & Process & $\begin{array}{l}\text { Program to communicate summary of hospitali- } \\
\text { zation with primary cardiologist at the time of } \\
\text { discharge }\end{array}$ \\
\hline 15. & Process & $\begin{array}{l}\text { Unplanned event debriefing program (rapid } \\
\text { escalation of care for transfer to CICU or less } \\
\text { than 7-day hospital readmission) }\end{array}$ \\
\hline 16. & Process & $\begin{array}{l}\text { Structured transfer handoff from ICU to inpatient } \\
\text { acute care unit. }\end{array}$ \\
\hline
\end{tabular}

performance. ${ }^{42}$ The MAGIC (Mid-Atlantic Group of Interventional Cardiology) registry collected data on long-term outcomes on 8 interventional procedures. ${ }^{43}$ Over 2400 procedures from 18 centers were collected and analyzed. C3PO (Congenital Cardiac Catheterization Project on Outcomes) started as an AHA funded project with 7 centers. Data were collected on all catheterization procedures and served as the basis for the Catheterization for Congenital Heart Disease Adjustment for Risk Method (CHARM) method to allow for differences in case mix between institutions and providers. ${ }^{44,45}$ CCISC (Congenital Cardiovascular Interventional Study Consortium) is an international voluntary consortium of adult and pediatric providers with a focus on complications and risk stratification as well as specific procedural outcomes. ${ }^{46}$

The IMPACT Registry of the National Cardiovascular Data Registry (NCDR) is a voluntary registry open to all centers and practices. Its 
TABLE 9 Interventional metrics

\begin{tabular}{|c|c|c|}
\hline Metric & Domain & Definition \\
\hline 1. & Outcome & $\begin{array}{l}\text { Clinical outcomes as detailed in the ACC IMPACT } \\
\text { registry }{ }^{53}\end{array}$ \\
\hline 2. & Outcome & $\begin{array}{l}\text { Proportion of diagnostic and interventional pro- } \\
\text { cedures with a major intra or postprocedure } \\
\text { adverse event. }\end{array}$ \\
\hline 3. & Outcome & $\begin{array}{l}\text { Proportion of patients who receive radiation } \\
\text { dose greater than 95th percentile of bench- } \\
\text { mark data (procedure specific). }{ }^{54}\end{array}$ \\
\hline 4. & Structure & $\begin{array}{l}\text { Participation in a national database for pediatric } \\
\text { and congenital heart disease cardiac catheter- } \\
\text { ization and intervention. }\end{array}$ \\
\hline 5. & Structure & $\begin{array}{l}\text { Participation in local quality improvement efforts } \\
\text { or national pediatric quality improvement net- } \\
\text { work (eg, radiation reduction) within focus on } \\
\text { improving process or outcomes in the cardiac } \\
\text { catheterization laboratory. }\end{array}$ \\
\hline 6. & Structure & Standardized adverse event (O/E) ratio reporting \\
\hline 7. & Process & $\begin{array}{l}\text { Precatheterization conference or extended time } \\
\text { out for all patients undergoing a catheteriza- } \\
\text { tion procedure }\end{array}$ \\
\hline 8. & Process & $\begin{array}{l}\text { Use of a formal and documented protocol/ } \\
\text { checklist for postcatheterization to ICU, ward } \\
\text { or recovery room. }\end{array}$ \\
\hline
\end{tabular}

intent is to gather information on diagnostic and interventional catheterization procedures on all pediatric patients and adult patients with congenital heart disease to ultimately improve patient outcomes. As of April 2016, IMPACT v.2 also collects safety and outcome data on pediatric electrophysiology procedures and transcatheter pulmonary valve replacement (TPVR). IMPACT v.2 is currently the only registry that is audited, validated and adjudicated. Risk adjustment was also added to IMPACT v. 2 in $2016 .{ }^{47-50}$ Process and outcome measures refined in these registries now help define quality in a pediatric cardiac catheterization program. ${ }^{51,52}$

Patient safety is critical in providing excellent clinical outcomes in interventional cardiology. Monitoring and improving safety in the interventional lab is a marker of a quality program. Quality programs incorporate procedural communication and checklists as well as take steps to reduce procedural related risks, such as radiation exposure. As with other areas of congenital heart care, participation in programs that track and share outcomes in an effort at collaborative learning is encouraged. Suggested Interventional metrics can be found in Table 9.

\section{9 | Noninvasive imaging}

Noninvasive cardiac imaging is an integral component of the congenital heart center, with accurate diagnostic imaging playing a key role in patient outcomes in all clinical areas of the center. The link between quality of imaging and patient outcome such as mortality or morbidity is not usually direct; hence, many quality metrics in this area focus on structure and process, with newer metrics focusing on other outcome measures related to safety, accuracy and value.
Structurally, a comprehensive congenital heart center should provide, or have ready access to, the full range of noninvasive imaging modalities: echocardiography (transthoracic, transesophageal, and fetal); cardiac MRI, and cardiac CT. Many centers will also use additional imaging modalities such as intracardiac echo or intravascular ultrasound. Imaging may be purely diagnostic, or may be integrated with interventions, such as the use of echocardiographic guidance in the operating or catheterization suites.

Process metrics in imaging focus on appropriateness of patient selection as well as study performance, interpretation, and reporting. Most of the available metrics focus on echocardiography given its role as the initial and primary noninvasive cardiac imaging modality. The Intersocietal Accreditation Commission (IAC) has established standards for the structure and processes of adult and pediatric echocardiography labs in North America. The standards are based on published guidelines related to training, structure, and performance of an echocardiography lab. ${ }^{55-59}$ However, these standards are considered a minimum and apply equally to small practices and large tertiary heart centers. It is expected that comprehensive congenital heart centers will meet metrics over and above the minimum standards for IAC accreditation.

To that end, a team established by the ACC's ACPC section has developed additional quality metrics specific to echocardiography, the use of which should be standard in a state of the art congenital heart center. Metrics currently available include: critical results reporting; adverse events with sedated pediatric echocardiography; comprehensive pediatric echocardiographic examination score; pediatric echocardiographic image quality score; pediatric echocardiographic diagnostic accuracy in pediatric transthoracic echocardiography. Additional quality metrics in development include: diagnostic accuracy in fetal echocardiography; appropriateness of pediatric outpatient echocardiography; adverse events with transesophageal echocardiography; comprehensive CMR examination score; and adverse events with pediatric CMR. These metrics begin to address the relationship between quality diagnostic imaging and patient outcomes.

Unlike subspecialties such as pediatric electrophysiology and interventional cardiology, to date there are no clinical data registries for pediatric/congenital noninvasive imaging. The American Society of Echocardiography (ASE) will be launching the first data registry for echocardiography in 2017, initially with a basic set of echo measurements, not unique to congenital heart disease including: LV size and function, aortic valve gradient, pulmonary artery pressure, and presence/absence of pericardial effusion. Over time, the complexity of data elements will be increased with the potential to add data elements applicable to congenital heart disease and the ability to further associate the quality of noninvasive imaging with patient outcome. ${ }^{60}$ For example, the Pediatric Heart Network is currently carrying out a study "to establish a Z-score database for common echocardiographic measurements based on a uniformly defined and racially diverse population of normal children from multiple centers over a wide geographic area." ${ }^{61}$ Suggested Noninvasive imaging metrics can be found in Table 10.

In addition to these noninvasive imaging metrics that should be considered currently, there are additional metrics that should be 
TABLE 10 Noninvasive imaging metrics

\begin{tabular}{|c|c|c|}
\hline Metric & Domain & Definition \\
\hline 1. & Outcome & $\begin{array}{l}\text { Adverse events with sedated pediatric echocar- } \\
\text { diography metric }\end{array}$ \\
\hline 2. & Outcome & Pediatric TTE diagnostic accuracy metric \\
\hline 3. & Structure & Participation in ACPC Quality Network \\
\hline 4. & Structure & $\begin{array}{l}\text { Comprehensive Noninvasive cardiac imaging } \\
\text { program: Transthoracic Echo; Transesophageal } \\
\text { Echo; Fetal Echo; Cardiac MRI; Cardiac CT; } \\
\text { Stress echo }\end{array}$ \\
\hline 5. & Structure & $\begin{array}{l}\text { Intersocietal Accreditation Commission Accred- } \\
\text { itation of Echocardiography Program }\end{array}$ \\
\hline 6. & Process & Pediatric TTE image quality metric \\
\hline 7. & Process & Comprehensive pediatric TTE metric \\
\hline 8. & Process & $\begin{array}{l}\text { Critical results reporting in pediatric echocardio- } \\
\text { graphy metric }\end{array}$ \\
\hline
\end{tabular}

discussed as potential next steps in measurement. These include: (1) comprehensive fetal echo metric, (2) fetal echo diagnostic accuracy metric, (3) TEE adverse events metric, (4) comprehensive CMR study metric, and (5) CMR adverse events metric.

\section{$2.10 \mid$ Nursing}

Nurses have a significant role in inpatient and outpatient clinical practice. It is critical to measure their contribution to the provision of safe, effective, efficient, equitable, timely, and patient/family centered care $^{62-65}$ Over the last decade, evidence linking the impact of pediatric nursing care on pediatric cardiovascular patient outcomes has supported the identification and development of nurse-sensitive quality measurement. ${ }^{66-72}$ The translation from evidence to implementation of pediatric cardiovascular nursing measurement for national benchmarking was the result of a charge received in 2008 from the American College of Cardiology (ACC) Pediatric Quality Metric Working Group (QMWG). To develop a nursing sensitive metric, the nursing project leader engaged expert clinicians, administrators and nurse scientists from 15 different institutions. Through consensus, the importance of nutrition for children with cardiac disease was highlighted and further identified as a critical component of pediatric cardiac nursing care that contributed to overall patient outcomes. Additionally, documentation of daily fluid intake was identified as a standardized activity performed by nurses, but there was no consistent documentation of assessment or measurement of nutritional intake of infants during hospitalization.

In its final form "Documentation of Nutrition" is a metric of daily recording of feeding status and calorie intake for all infants one month or older admitted for surgical intervention or medical intervention/ management for more than one 24-hour period. Following an internal and external review and endorsement of the measure, 15 pediatric cardiovascular programs implemented the measure and successfully improved the practice of daily documentation of nutrition. The ACC QMWG nursing experience demonstrated a number of successes: (1) development of a collaborative, consensus-based approach among pediatric cardiac nurse scientists, administrators, and clinical experts to identify and develop a quality nursing measurement; (2) feasibility of implementing a measure and data collection strategy in 15 institutions across the country; and (3) a commitment in identification and testing of other measures in a consensus based manner.

This effort provided the impetus for the inception of the Consortium for Congenital Cardiac Care Measurement of Nursing Practice (C4-MNP). ${ }^{62}$ Donabedian's framework of structure, process and outcomes along with the Institute of Medicine's quality domains are used to guide a national community of researchers, administrators and expert clinicians committed to rigorous measurement of the quality of care required by nurses who participate in achieving optimal outcomes for children with cardiac disease. ${ }^{8,62,73}$ Today the C4-MNP has expanded the scope of nurse sensitive quality measurement to inform optimal staffing models, work environments and evidence based practice with collaboration of 32 pediatric cardiovascular programs in the United States. ${ }^{8,62,73}$

In 2015 the ACC published a health policy statement on cardiovascular team-based care and the role of advanced practice providers. ${ }^{74}$ This manuscript emphasized the role of nurses and advanced practice providers, as well as other clinical support staff (eg, pharmacy, discharge coordinators, nutritionists) to enhance efficiency and patient clinical outcomes. With every team member functioning at top of license, patient outcomes such as medication compliance and decrease in unplanned readmissions can be measured. Importantly, these teams help to coordinate patient care between the inpatient and outpatient arenas. Suggested Nursing metrics can be found in Table 11.

\section{3 | DISCUSSION}

This manuscript provides guidance to programs responsible for the care of patients with congenital heart disease. Building on the 2002 American Academy of Pediatrics published "Guidelines for Pediatric Cardiovascular Centers," this work applied the Donebedian model to identify important outcome, structure and process metrics currently used

TABLE 11 Nursing metrics

\begin{tabular}{|c|c|c|}
\hline Metric & Domain & Definition \\
\hline 1. & Structure & $\begin{array}{l}\text { Overall Years of Nursing Experience: Unit-level } \\
\text { measure of the percentage of registered } \\
\text { nursing staff providing patient care that has 0- } \\
2 \text { years of any clinical experience }\end{array}$ \\
\hline 2. & Structure & $\begin{array}{l}\text { Bachelor of Science in Nursing (BSN) Education: } \\
\text { Unit-level measure of the percentage of } \\
\text { registered nursing staff who are at least BSN- } \\
\text { prepared }\end{array}$ \\
\hline 3. & Structure & $\begin{array}{l}\text { Nursing Certification: Unit-level measure of the } \\
\text { percentage of registered nursing staff provid- } \\
\text { ing patient care who are CCRN or CPN } \\
\text { certified }\end{array}$ \\
\hline 4. & Process & $\begin{array}{l}\text { Documentation of Nutrition: Monthly measure } \\
\text { of daily documentation of feeding status and } \\
\text { received calories } / \mathrm{kg} / \text { day for infants }</=30 \\
\text { days of age admitted for surgical or medical } \\
\text { intervention for }>24 \text {-hour period }\end{array}$ \\
\hline
\end{tabular}


or proposed by groups of clinicians, administrators, and patients/families. ${ }^{1}$ The intent of this work is to provide standardization around how congenital heart centers might measure their program characteristics in areas that are felt to be related to high value, safe clinical care resulting in excellent clinical outcomes.

This approach to defining metrics was unique given that we took a broad collaborative approach to define potentially important measures. While we used the Donabedian framework of focus on process, structure and outcome metrics, we emphasize that patient outcomes and the value they provide to patients should be central to what programs measure and report. Our methodology allowed clinicians, administrators, and parents to collectively decide what matters most. While these metrics may not be perfect, they will allow us to understand some of the variability that may exist among centers caring for patients with congenital heart disease. It has been shown in a broad range of industries, including healthcare that reduction in process variation typically results in better overall outcomes. ${ }^{75,76}$ This concept has been demonstrated by a number of groups within the field of congenital heart disease. ${ }^{77,78}$ Once we understand the variation that exists among care center structure and processes we can collaboratively work to reduce that variability and expect to see improved overall outcomes.

Measuring a standard set of outcome, structure and process metrics at a program level is especially important for our families. As noted by those involved in the data transparency movement, patients and families are clamoring for comparable information from programs as they decide where to seek care for themselves or their loved ones. ${ }^{4}$ As clinicians, we have the responsibility to provide accurate and impactful data to our patients to help them make informed decisions about their care. In nearly every domain of metric development (Table 1 ) there is need for more and better measures of short- and long-term outcomes. Because outcomes are the heart of what these centers strive for, and what patients demand, it is critical for clinicians and programs to close this outcome metric gap in the near future.

While we believe that the metrics listed in this report are important to track at centers caring for patients with congenital heart disease, we make these recommendations fully aware of the environment of "over measurement" in which we currently operate clinically. We are in a period where healthcare has been flooded with measurement, often mandated by regulatory bodies and at times self-imposed. A recent $\mathrm{NIH}$ workgroup has addressed the issue of exponentially increasing data and the need for collaborative agreement regarding key quality metrics and the concept of big data. ${ }^{73}$ As noted by Berwick, "intemperate measurement is as unwise and irresponsible as is intemperate healthcare."79 Specific to our field, Redington recently noted similar frustrations with collecting massive amounts of information into clinical registries, and the cost associated with this work. ${ }^{80}$ Part of the angst around the abundance of metrics in healthcare is the cost of collecting the data required to report many metrics. ${ }^{81}$ As we propose additional metrics for our field, we agree with the sentiment that we need to focus on "measuring what matters" and doing so in the most efficient and affordable way possible. The current effort, initiated at the 2016 Congenital Heart Community Day, provides an opportunity for clinicians, patients and administrators to collaboratively define "what matters." Going forward, it will be wise for these metrics to be matched to ongoing or existing work, rather than to invent new methods to measure and track these metrics. Some examples of potential systems that might be used to track program level metrics include the American College of Cardiology Adult Congenital and Pediatric Quality Network (QNet) or using this group of metrics to influence the metrics chosen for measurement by the US News and World Report. ${ }^{20}$

\section{4 | CONCLUSION}

Dynamic forces such as the change in healthcare reimbursement, increasing demand for transparency of outcomes, and evolving diagnostic and treatment technology and procedures provide the rationale for collaboration amongst pediatric cardiology centers today. This collaborative effort has helped to define the most critical quality metrics which can lead to development of established center-level national benchmarks. The elimination of unnecessary variability is an important local concept, ensuring consistent care amongst providers, but also can be applied to the national effort between and among centers. Engagement of patients and families to define meaningful structure, process, and outcome metrics will ensure the greatest return on the investment of our time and collective efforts.

\section{CONFLICTS OF INTEREST}

None

\section{AUTHOR CONTRIBUTIONS}

Primary Author and Editor: Anderson

Ambulatory section and final editing: Chowdhury

Nursing section and final editing: Connor

ACHD section and final editing: Daniels

Noninvasive imaging section and final editing: Fleishman

Cardiac Critical Care section and final editing: Gaies

CT surgery section and assisted with final editing: Jacobs

EP section and assisted with final editing: Kugler

Inpatient units section and final editing: Madsen

Conceived the project and editing: Beekman

Final editing: Lihn

Administrative section and final editing: Stewart-Huey

Interventional section and final editing: Vincent

Primary writing and editing throughout the process: Campbell

\section{ORCID}

Jeffery B. Anderson MD (DD http://orcid.org/0000-0001-9155-2238

\section{REFERENCES}

[1] Section on Cardialogy and Cardiac Surgery. American Academy of Pediatrics: Guidelines for pediatric cardiovascular centers. Pediatrics. 2002;109(3):544-549.

[2] Pasquali SK, Jacobs JP, Farber GK, et al. Report of the National Heart, Lung, and Blood Institute Working Group: an integrated 
network for congenital heart disease research. Circulation. 2016;133 (14):1410-1418.

[3] Asante-Korang A, Jacobs JP. Big Data and paediatric cardiovascular disease in the era of transparency in healthcare. Cardiol Young. 2016;26(08):1597-1602.

[4] Lihn SL, Kugler JD, Peterson LE, Lannon CM, Pickles D, Beekman $\mathrm{RH}$. 3rd. Transparency in a pediatric quality improvement collaborative: a passionate journey by NPC-QIC clinicians and parents. Congenit Heart Dis. 2015;10(6):572-580.

[5] Shaw K, Cassel CK, Black C, Levinson W. Shared medical regulation in a time of increasing calls for accountability and transparency: comparison of recertification in the United States, Canada, and the United Kingdom. JAMA. 2009;302(18):2008-2014.

[6] Herrin J, Harris KG, Kenward K, Hines S, Joshi MS, Frosch DL. Patient and family engagement: a survey of US hospital practices. BMJ Qual Saf. 2016;25(3):182-189.

[7] Agency for Healthcare Research and Quality. The Six Domains of Health Care Quality. Rockville, MD: Agency for Healthcare Research and Quality; 2016.

[8] Donabedian A. The quality of care. How can it be assessed?. JAMA. 1988;260(12):1743-1748.

[9] Porter ME. What is value in health care? N Engl J Med. 2010;363 (26):2477-2481.

[10] HCAHPS. Web site. http://www.hcahpsonline.org/home.aspx

[11] Carlson B. Controlling the cost of care through clinical pathways. Biotechnol Healthcare. 2009;6:23-26.

[12] Warnes CA, Williams RG, Bashore TM, et al. ACC/AHA 2008 Guidelines for the Management of Adults with Congenital Heart Disease: a report of the American College of Cardiology/American Heart Association Task Force on Practice Guidelines (writing committee to develop guidelines on the management of adults with congenital heart disease). Circulation. 2008;118(23):e714-e833.

[13] Gurvitz M, Marelli A, Mangione-Smith R, Jenkins K. Building quality indicators to improve care for adults with congenital heart disease. J Am Coll Cardiol. 2013;62(23):2244-2253.

[14] Quality Metrics. Web site. https://cvquality.acc.org/initiatives/acpcquality-network/quality-metrics

[15] Webb GD, Williams RG. Care of the adult with congenital heart disease: introduction. J Am Coll Cardiol. 2001;37(5):1166

[16] Mylotte D, Pilote L, lonescu-Ittu R, et al. Specialized adult congenital heart disease care: the impact of policy on mortality. Circulation. 2014;129(18):1804-1812.

[17] Accreditation Program. Web site. https://www.achaheart.org/provider-support/accreditation-program

[18] Chan PS, Oetgen WJ, Buchanan D, et al. Cardiac performance measure compliance in outpatients: the American College of Cardiology and National Cardiovascular Data Registry's PINNACLE (Practice Innovation And Clinical Excellence) program. J Am Coll Cardiol. 2010;56(1):8-14.

[19] Chowdhury D, Gurvitz M, Marelli A, et al. Development of quality metrics in ambulatory pediatric cardiology. J Am Coll Cardiol. 2017; 69(5):541-555.

[20] Quality Networks. Web site. https://cvquality.acc.org/initiatives/ acpc-quality-network

[21] Campbell RM, Douglas PS, Eidem BW, Lai WW, Lopez L, Sachdeva R. ACC/AAP/AHA/ASE/HRS/SCAI/SCCT/SCMR/SOPE 2014 appropriate use criteria for initial transthoracic echocardiography in outpatient pediatric cardiology: a report of the American College of Cardiology Appropriate Use Criteria Task Force, American Academy of Pediatrics, American Heart Association, American Society of
Echocardiography, Heart Rhythm Society, Society for Cardiovascular Angiography and Interventions, Society of Cardiovascular Computed Tomography, Society for Cardiovascular Magnetic Resonance, and Society of Pediatric Echocardiography. J Am Soc Echocardiogr. 2014; 27(12):1247-1266.

[22] Clauss SB, Anderson JB, Lannon C, et al. Quality improvement through collaboration: the National Pediatric Quality improvement Collaborative initiative. Curr Opin Pediatr. 2015;27(5):555-562.

[23] Rathod RH, Farias M, Friedman KG, et al. A novel approach to gathering and acting on relevant clinical information: SCAMPs. Congenit Heart Dis. 2010;5(4):343-353.

[24] Friedman KG, Kane DA, Rathod RH, et al. Management of pediatric chest pain using a standardized assessment and management plan. Pediatrics. 2011;128(2):239-245.

[25] Friedman KG, Rathod RH, Farias M, et al. Resource utilization after introduction of a standardized clinical assessment and management plan. Congenit Heart Dis. 2010;5(4):374-381.

[26] Paris Y, Toro-Salazar OH, Gauthier NS, et al. Regional implementation of a pediatric cardiology syncope algorithm using standardized clinical assessment and management plans (SCAMPS) methodology. J Am Heart Assoc. 2016;5:e002931.

[27] Porras D, Brown DW, Rathod R, et al. Acute outcomes after introduction of a standardized clinical assessment and management plan (SCAMP) for balloon aortic valvuloplasty in congenital aortic stenosis. Congenit Heart Dis. 2014;9(4):316-325.

[28] Jacobs JP, Jacobs ML, Austin EH, 3rd, et al. Quality measures for congenital and pediatric cardiac surgery. World J Pediatr Congenit Heart Surg. 2012;3(1):32-47.

[29] Jacobs JP, Mayer JE, Jr., Mavroudis C, et al. The society of thoracic surgeons congenital heart surgery database: 2016 update on outcomes and quality. Ann Thorac Surg. 2016;101(3):850-862.

[30] Jacobs JP, O'Brien SM, Pasquali SK, et al. The importance of patient-specific preoperative factors: an analysis of the society of thoracic surgeons congenital heart surgery database. Ann Thorac Surg. 2014;98(5):1653-1658. discussion 1658-9.

[31] Pasquali SK, Jacobs ML, O'Brien SM, et al. Impact of patient characteristics on hospital-level outcomes assessment in congenital heart surgery. Ann Thorac Surg. 2015;100(3):1071-1076. discussion 1077.

[32] Jacobs JP, O'Brien SM, Pasquali SK, et al. The society of thoracic surgeons congenital heart surgery database mortality risk model: part 2-clinical application. Ann Thorac Surg. 2015;100:1063-1068. discussion 1068-70.

[33] Kugler JD, Danford DA, Houston KA, Felix G. Pediatric radiofrequency catheter ablation registry success, fluoroscopy time, and complication rate for supraventricular tachycardia: comparison of early and recent eras. J Cardiovasc Electrophysiol. 2002;13(4): 336-341.

[34] Van Hare GF, Carmelli D, Smith WM, et al. Prospective assessment after pediatric cardiac ablation: design and implementation of the multicenter study. Pacing Clin Electrophysiol. 2002;25(3):332-341.

[35] Seslar SP, Kugler J, Batra AS, et al. The Multicenter Pediatric and Adult Congenital EP Quality (MAP-IT) initiative-rationale and design: report from the pediatric and congenital electrophysiology society's MAP-IT taskforce. Congenit Heart Dis. 2013;8:381-392.

[36] Triedman JK, Pfeiffer P, Berman A, et al. COMPASS: a novel riskadjustment model for catheter ablation in pediatric and congenital heart disease patients. Congenit Heart Dis. 2013;8:393-405.

[37] Epstein AE, DiMarco JP, Ellenbogen KA, et al. ACC/AHA/HRS 2008 Guidelines for Device-Based Therapy of Cardiac Rhythm Abnormalities: a report of the American College of Cardiology/American 
Heart Association Task Force on Practice Guidelines (Writing Committee to Revise the ACC/AHA/NASPE 2002 Guideline Update for Implantation of Cardiac Pacemakers and Antiarrhythmia Devices): developed in collaboration with the American Association for Thoracic Surgery and Society of Thoracic Surgeons. Circulation. 2008; 117:e350-e408.

[38] Jenkins KJ, Correa A, Feinstein JA, et al. Noninherited risk factors and congenital cardiovascular defects: current knowledge: a scientific statement from the American Heart Association Council on Cardiovascular Disease in the Young: endorsed by the American Academy of Pediatrics. Circulation. 2007;115(23):2995-3014.

[39] Mahle WT, Nicolson SC, Hollenbeck-Pringle D, et al. Utilizing a collaborative learning model to promote early extubation following infant heart surgery. Pediatr Crit Care Med. 2016;17(10):939-947.

[40] McCrindle BW. Independent predictors of long-term results after balloon pulmonary valvuloplasty. Valvuloplasty and Angioplasty of Congenital Anomalies (VACA) Registry Investigators. Circulation. 1994;89(4):1751-1759.

[41] Stanger P, Cassidy SC, Girod DA, Kan JS, Lababidi Z, Shapiro SR. Balloon pulmonary valvuloplasty: results of the Valvuloplasty and Angioplasty of Congenital Anomalies Registry. Am J Cardiol. 1990; 65(11):775-783.

[42] Jones TK, Latson LA, Zahn E, et al. Results of the U.S. multicenter pivotal study of the HELEX septal occluder for percutaneous closure of secundum atrial septal defects. J Am Coll Cardiol. 2007;49 (22):2215-2221.

[43] Everett AD, Ringel R, Rhodes JF, et al. Development of the MAGIC congenital heart disease catheterization database for interventional outcome studies. J Interven Cardiol. 2006;19(2):173-177.

[44] Bergersen L, Gauvreau K, Foerster SR, et al. Catheterization for Congenital Heart Disease Adjustment for Risk Method (CHARM). JACC Cardiovasc Interventions. 2011;4(9):1037-1046.

[45] Bergersen L, Gauvreau K, Marshall A, et al. Procedure-type risk categories for pediatric and congenital cardiac catheterization. Circ Cardiovasc Interven. 2011;4(2):188-194.

[46] Forbes TJ, Garekar S, Amin Z, et al. Procedural results and acute complications in stenting native and recurrent coarctation of the aorta in patients over 4 years of age: a multi-institutional study. Catheter Cardiovasc Interven. 2007;70(2):276-285.

[47] Holzer R, Beekman R, Benson L, et al. Characteristics and safety of interventions and procedures performed during catheterisation of patients with congenital heart disease: early report from the national cardiovascular data registry. Cardiol Young. 2016;26(06):1202-1212.

[48] Martin GR, Beekman RH, Ing FF, et al. The IMPACT registry: improving pediatric and adult congenital treatments. Semin Thoracic Cardiovasc Surg Pediatr Cardiac Surg Annu. 2010;13(1):20-25.

[49] Moore JW, Vincent RN, Beekman RH, 3rd, et al. Procedural results and safety of common interventional procedures in congenital heart disease: initial report from the National Cardiovascular Data Registry. J Am Coll Cardiol. 2014;64(23):2439-2451.

[50] Rn V, J M, Rh B, et al. Procedural characteristics and adverse events in diagnostic and interventinoal catheterisations in paediatric and adult CHD: initial report from the IMPACT Registry. Cardiol Young. 2015;26:1-9.

[51] Jayaram N, Beekman RH, 3rd, Benson L, et al. Adjusting for risk associated with pediatric and congenital cardiac catheterization: a report from the NCDR IMPACT registry. Circulation. 2015;132: 1863-1870.

[52] Nicholson GT, Gao K, Kim SI, et al. Direct physician reporting is associated with reductions in radiation exposure in pediatric cardiac catheterizations. Catheter Cardiovasc Interven. 2015;86(5):834-840.
[53] Masoudi FA, Ponirakis A, de Lemos JA, et al. Trends in U.S. cardiovascular care: 2016 report from 4 ACC National Cardiovascular Data Registries. J Am Coll Cardiol. 2017;69(11):1427-1450.

[54] Cevallos PC, Armstrong AK, Glatz AC, et al. Radiation dose benchmarks in pediatric cardiac catheterization: a prospective multi-center C3PO-QI study. Catheterization Cardiovasc Interven. 2017;90(2):269-280.

[55] Ayres NA, Miller-Hance W, Fyfe DA, et al. Indications and guidelines for performance of transesophageal echocardiography in the patient with pediatric acquired or congenital heart disease: report from the task force of the Pediatric Council of the American Society of Echocardiography. J Am Soc Echocardiogr. 2005;18(1):91-98.

[56] Donofrio MT, Moon-Grady AJ, Hornberger LK, et al. Diagnosis and treatment of fetal cardiac disease: a scientific statement from the American Heart Association. Circulation. 2014;129(21):2183-2242.

[57] Lai WW, Geva T, Shirali GS, et al. Guidelines and standards for performance of a pediatric echocardiogram: a report from the Task Force of the Pediatric Council of the American Society of Echocardiography. J Am Soc Echocardiogr. 2006;19(12):1413-1430.

[58] Srivastava S, Printz BF, Geva T, et al. Task Force 2: pediatric cardiology fellowship training in noninvasive cardiac imaging. J Am Coll Cardiol. 2015;66(6):687-698.

[59] Picard MH, Adams D, Bierig SM, et al. American Society of Echocardiography recommendations for quality echocardiography laboratory operations. J Am Soc Echocardiogr. 2011;24(1):1-10.

[60] Klein The ASE ImageGuideEcho registry: taking care of business. J Am Soc Echocardiogr. 2017;30:A17-A19.

[61] Echo Z-Score. http://www.pediatricheartnetwork.org/Studies/CurrentStudies/EchoZScore.aspx

[62] Connor JA, Mott S, Green A, Larson C, Hickey P. Measurement of quality of nursing practice in congenital cardiac care. Am J Crit Care. 2016;25(2):128-135

[63] Institute of Medicine Committee on the Robert Wood Johnson Foundation Initiative on the Future of Nursing atloM. The Future of Nursing: Leading Change, Advancing Health. Washington, DC: National Academies Press (US); 2011.

[64] Naylor MD. Advancing the science in the measurement of health care quality influenced by nurses. Med Care Res Rev. 2007;64(2 Suppl):144s-169s.

[65] Needleman J, Kurtzman ET, Kizer KW. Performance measurement of nursing care: state of the science and the current consensus. Med Care Res Rev. 2007;64(2 Suppl):10s-43s.

[66] Anderson JB, Beekman RH, 3rd, Eghtesady P, et al. Predictors of poor weight gain in infants with a single ventricle. J Pediatr. 2010; 157(3):407-413, 413.e1.

[67] Hickey P, Gauvreau K, Connor J, Sporing E, Jenkins K. The relationship of nurse staffing, skill mix, and Magnet recognition to institutional volume and mortality for congenital heart surgery. J Nursing Admin. 2010;40(5):226-232.

[68] Hickey PA, Gauvreau K, Curley MA, Connor JA. The effect of critical care nursing and organizational characteristics on pediatric cardiac surgery mortality in the United States. J Nurs Admin. 2013;43(12):637-644.

[69] Hickey PA, Gauvreau K, Jenkins K, Fawcett J, Hayman L. Statewide and national impact of California's Staffing Law on pediatric cardiac surgery outcomes. J Nurs Admin. 2011;41(5):218-225.

[70] Hickey PA, Gauvreau K, Tong E, Schiffer NP, Connor JA. Pediatric cardiovascular critical care in the United States: nursing and organizational characteristics. Am J Crit Care. 2012;21(4):242-250.

[71] Hickey PA, Pasquali SK, Gaynor JW, et al. Critical care nursing's impact on pediatric patient outcomes. Ann Thorac Surg. 2016;102 (4):1375-1380. 
[72] Uzark K, Wang Y, Rudd N, et al. Interstage feeding and weight gain in infants following the Norwood operation: can we change the outcome?. Cardiol Young. 2012;22(05):520-527.

[73] Connor JA, Larson C, Baird J, Hickey PA. Use of a pediatric cardiovascular nursing consortium for development and evaluation of quality measures: the C4-MNP experience. J Pediatr Nurs. 2016;31 (5):471-477.

[74] Brush JE, Jr., Handberg EM, Biga C, et al. 2015 ACC health policy statement on cardiovascular team-based care and the role of advanced practice providers. J Am Coll Cardiol. 2015;65(19):21182136.

[75] Margolis PA, Peterson LE, Seid M. Collaborative Chronic Care Networks (C3Ns) to transform chronic illness care. Pediatrics. 2013;131 (Suppl 4):S219-S223.

[76] Lannon CM, Peterson LE. Pediatric collaborative networks for quality improvement and research. Acad Pediatr. 2013;13(6):S69-S74.

[77] Anderson JB, Beekman RH, 3rd, Kugler JD, et al. Improvement in interstage survival in a national pediatric cardiology learning network. Circ Cardiovasc Qual Outcomes. 2015;8(4):428-436.
[78] Anderson JB, Beekman RH, 3rd, Kugler JD, et al. Use of a learning network to improve variation in interstage weight gain after the Norwood operation. Congen Heart Dis. 2014;9(6):512-520.

[79] Berwick DM. Era 3 for medicine and health care. JAMA. 2016;315 (13):1329-1330.

[80] Redington AN. Consolidate or constipate: what are we going to do with all our registries? Congenit Heart Dis. In Press.

[81] Schuster MA, Onorato SE, Meltzer DO. Measuring the Cost of Quality Measurement: A Missing Link in Quality Strategy. JAMA. 2017;318:1219-1220.

How to cite this article: Anderson JB, Chowdhury D, Connor $\mathrm{JA}$, et al. Optimizing patient care and outcomes through the congenital heart center of the 21st century. Congenital Heart Disease. 2018;13:167-180. https://doi.org/10.1111/chd.12575 